\title{
Characterization of Hybrid Composites Produced with Mats Made Using Different Methods
}

Cristiane Aurélia Borges Vieira ${ }^{\mathrm{a}}$, Samuel Brando Susin ${ }^{\mathrm{a}}$, Estevão Freire ${ }^{\mathrm{a}}$, Sandro Campos Amico ${ }^{\mathrm{b}}$, Ademir José Zattera ${ }^{\mathrm{a} *}$

\author{
${ }^{a}$ Centro de Ciências Exatas e Tecnologia - CCET, Universidade de Caxias do Sul - UCS, \\ Caxias do Sul - RS, Brazil \\ ${ }^{\mathrm{b}} P P G E M$, Rio Grande do Sul Federal University - UFRGS, \\ Porto Alegre - RS, Brazil
}

Received: May 19, 2009; Revised: September 3, 2009

\begin{abstract}
This work is focused on the development and evaluation of manufacturing methods to produce short fibers hybrid mats. Different methods were developed, including: aqueous and fluidized bed. Composites were molded to help evaluating the produced mats. The analysis showed that composites manufactured by the fluidized bed method presented the best mechanical properties.
\end{abstract}

Keywords: hybrid composite, glass fiber, sisal fiber, mat, manufacturing methods

\section{Introduction}

In recent years, many research works were developed in the field of natural fiber reinforced composites for using in several applications ${ }^{1,2}$. Properties such as low density, attractive cost and biodegradability $^{3,4}$ are relevant characteristics in choosing these materials as reinforcement.

The possibility of mixing reinforcements (i.e. to use hybrid composites) is attractive because it allows the designing of composites with mechanical performance to meet the needs of the product. The benefits of replacing synthetic fibers for natural ones, even if only partially, are mainly ecological, because the natural reinforcement is recyclable (through thermal recycling). Besides, the natural fibers are biodegradable and lighter than glass fibers ${ }^{5}$, which reverts as fuel reduction when this material is used by the automotive industry. The use of naturals fibers, abundant in Brazil, also brings social and economic benefits.

The mechanical properties of polymers reinforced by fibers do not depend only on the characteristics of matrix and fibers, but also on the ability to ensure efficient mechanical stress transfer between matrix and fiber ${ }^{6}$. Many studies have focused on the improvement of the adhesion between fiber and matrix by modifying the fiber and /or the polymer matrix using physical, chemical or mechanical methods. The surface of glass fibers is generally modified by sizings. The total mass of sizing added to the glass fiber is around 0.2 to $2 \mathrm{wt}$. (\%) of the fiber ${ }^{6,7}$.

In this work, several methods to manufacture hybrid mats using a mixture of sisal fiber and glass fiber were studied. The evaluation of the developed hybrid mats was performed through the mechanical analysis of processed composites.

\section{Experimental}

\subsection{Materials}

Sisal fibers were supplied by Sisalândia Fios Naturais Ltda. Glass fibers (EC 2400 P207) were supplied by Vetrotex S.A and unsaturated polyester and methyl-ethyl-ketone peroxide (p-MEK) from Elekeiroz S.A, (code: UC 2090).

\subsection{Fiber treatment}

The sisal rope was cut into $3 \mathrm{~cm}$ long fibers and the fibers were washed $(100 \mathrm{~mL}$ of water per gram of fiber) in distilled water for 30 minutes. The fibers were dried in an oven with ventilation for 180 minutes at $60{ }^{\circ} \mathrm{C}$.

\subsection{Mat manufacturing methods}

The two methods used for mat manufacturing are described in Table 1. In these methods, a mixture of sisal and glass was used. The total fiber volumetric fraction of the composites used in this work was $25 \%$, within this percentage, the volumetric relation between glass fiber and sisal fiber was modified according to the following compositions:
a) $100 \%$ glass fiber and $0 \%$ sisal fiber;
b) $75 \%$ glass fiber and $25 \%$ sisal fiber;
c) $50 \%$ glass fiber and $50 \%$ sisal fiber;
d) $25 \%$ glass fiber and $75 \%$ sisal fiber;
e) $0 \%$ glass fiber and $100 \%$ sisal fiber.

\subsection{Composite manufacturing}

In order to prepare hybrid composites, hot compression molding was used. The dimensions of the stainless steel mold were $17 \times 17 \times 0.3 \mathrm{~cm}$. The composite was molded with $2 \mathrm{MPa}$, at $60{ }^{\circ} \mathrm{C}$ for 95 minutes. After curing, the composite was placed in a cold press until room temperature was reached.

\subsection{Characterization of the composites}

Water absorption tests were carried out according to ASTM D570 ${ }^{[8]}$. For these tests, 6 samples $(1.5 \times 1.5 \times 0.3 \mathrm{~cm})$ were extracted from the composites plates and immersed for 48 hours in distilled water at room temperature.

Tensile tests were performed using a Universal Testing Machine, EMIC $^{\circledR}$ model DL 3000, according to ASTM D3039 ${ }^{[9]}$. Six samples were tested for each composite. Test was conducted at a crosshead speed of $2 \mathrm{~mm} / \mathrm{min}$. Impact tests were performed in an Izod Impact Tester, model CEAST Resil 25, in accordance with ASTM D256 ${ }^{[10]}$. Six samples were tested for each composite. 
The cross-section of the tensile fractured surface of the hybrid composite specimens was studied by scanning electron microscopy (SEM), in a Jeol ${ }^{\circledR}$ microscope, model 6060.

\section{Results and Discussion}

The water absorption of the composites can be seen in Figure 1. It is clear from this figure the more hygroscopic behavior of the sisal fiber in relation to the glass fiber, as also observed by Wambua

Table 1. Methods for the manufacturing of mats.

\begin{tabular}{ll}
\hline \multicolumn{1}{c}{ Method } & \multicolumn{1}{c}{ Description } \\
\hline 1-Aqueous & $\begin{array}{l}\text { Deposition of fibers in a liquid phase - } \\
\text { Distilled Water } \\
\text { 2-Non-aqueous }\end{array}$ \\
& $\begin{array}{l}\text { Deposition of fiber in a gas phase - } \\
\text { Fluidized Bed }\end{array}$ \\
\hline
\end{tabular}

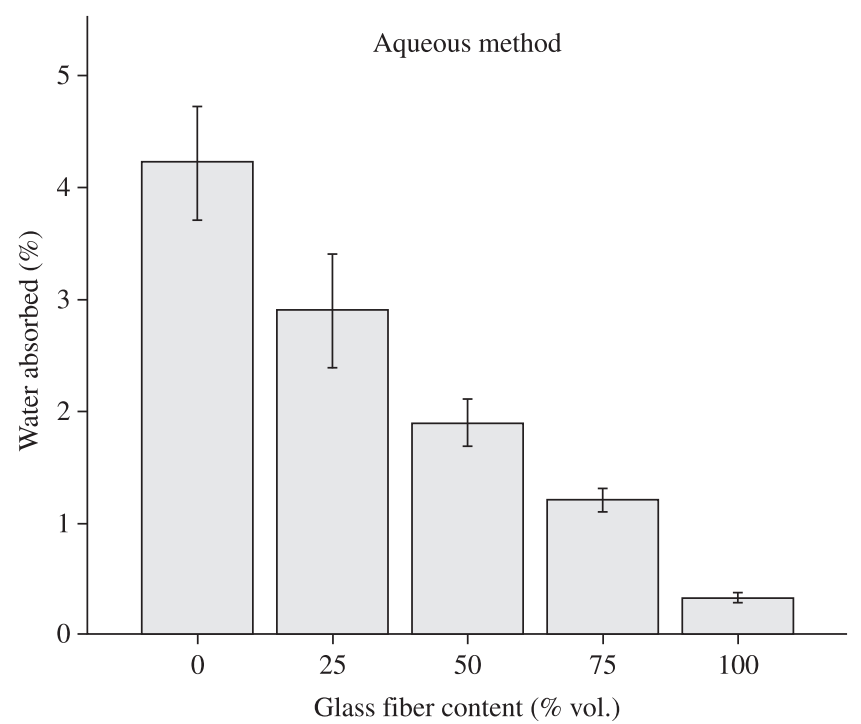

Figure 1. Water absorption in the composites in relation to the glass fiber content - Aqueous method.

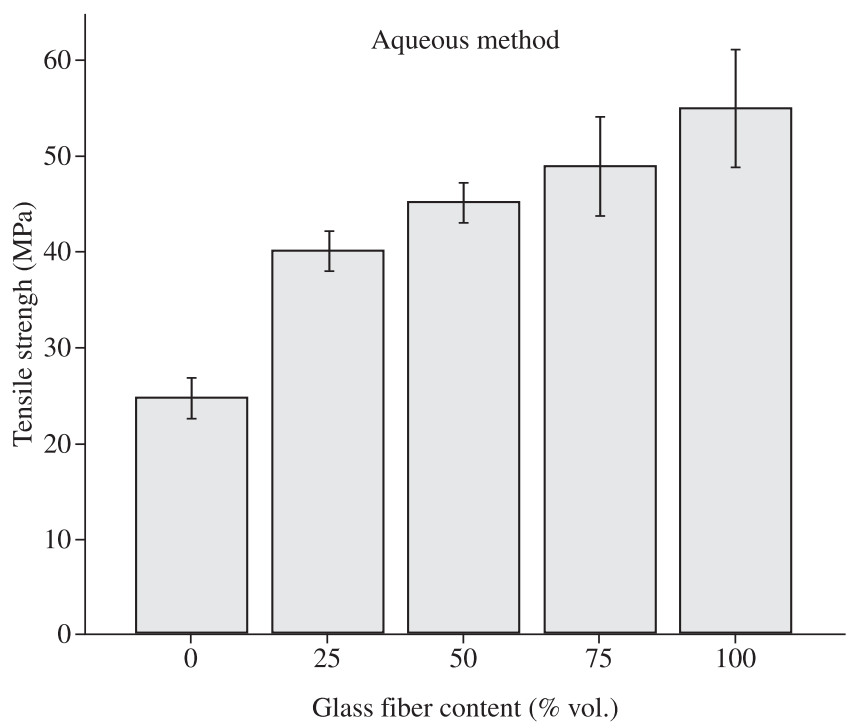

Figure 2. Tensile strength of the composites in relation to the glass fiber content of the mats - Aqueous method. et al. ${ }^{11}$, i.e. the higher the glass fiber content in the reinforcement the lower the water absorption of the composites. The composites containing only sisal fibers absorb around 15 times more water than those containing only glass fibers.

The results of mechanical properties (Figure 2) show that the increasing in glass fiber content yields an increase in tensile strength. This justifies the using of hybrid composites, since the addition of glass fibers produced a composite with better mechanical performance.

Analyzing the results of tensile strength (Figure 2), it was observed that the composites with a higher content of sisal fiber showed less deviation of measurements, i.e. the results are more reproducible. It may also be said that the glass fiber cooperates positively in the composites in which sisal fiber predominates. In Figure 3, the differences in morphology between sisal fiber and glass fibers can be seen.

The same findings about the tensile strength results can be applied to the impact strength results (Figure 4). The impact results show that an increase in glass fiber content generates an increase in impact strength. This increase can be explained by the stronger adhesion of the matrix to the glass fiber in relation to the sisal fiber. Thus, the energy is more efficiently transferred from the matrix to the fiber in the composites with higher glass fiber content. If there was no energy transfer between matrix/fiber, the results would be nearly constant, close to that of the

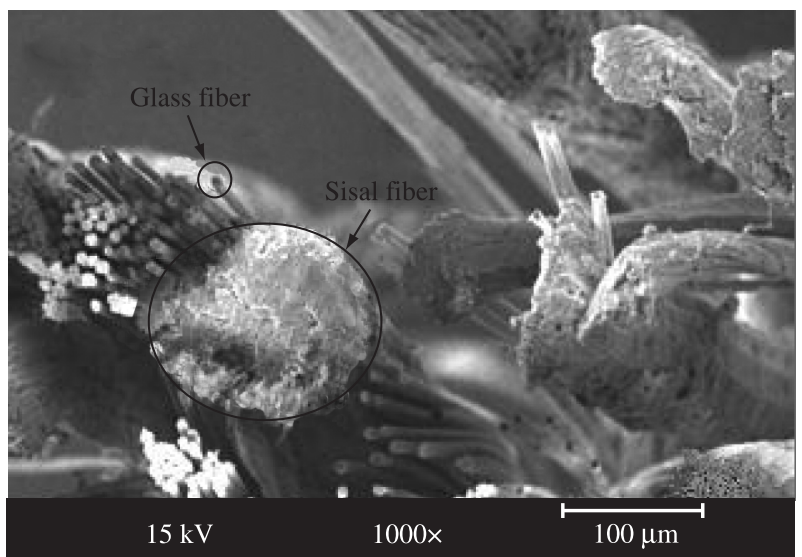

Figure 3. SEM micrograph of a tensile fractured composite with $75 \%$ glass fiber in the reinforcement.

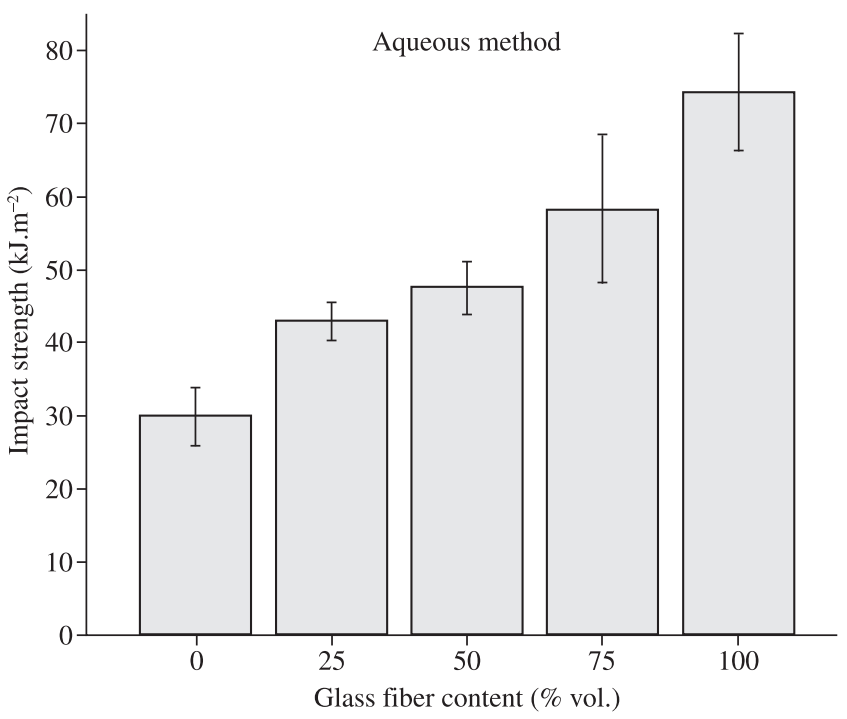

Figure 4. Impact strength of the composites in relation to the glass fiber content of the mats - Aqueous method. 
virgin polyester resin ${ }^{12}$. In the same way, the composites with lower glass fiber content (25 and 50\%) showed more reproducibility.

From these results, it was observed that the $50 \%$ glass fiber content may be technologically interesting. This composition is cheaper than that with $100 \%$ glass fiber content, and with superior mechanical properties than the $100 \%$ sisal fiber composition.

After the definition of the most interesting composition, another method for mat manufacturing was evaluated, the non-aqueous method (bed fluidized with air). Figures 5 and 6 show the visual aspect of the mats produced using different methods.

In the aqueous method, two phenomena occur, aggregation of fibers due to the pressure on the mat due to the water, and aggregation of glass fibers in contact with the water (liquid phase). The lowest glass fiber/water chemical compatibility in relation to glass fiber/ glass fiber leads to the production of agglomerates of fiber glass in the aqueous phase. These agglomerates hinder the flow of resin through the mats manufactured by the aqueous method. These agglomerates decrease the interfacial area between glass fibers and polyester resin ultimately decreasing the performance of the composites. Analyzing the morphology of the mat manufactured using the aqueous method (Figure 5), the advantages of the fluidized bed process became evident. The mats manufactured with the fluidized bed method show less agglomeration of fibers, promoting resin flow within the mat.

Analysis of Figure 7 (tensile and impact strength results) shows that the composites obtained with mats produced with the aqueous method show poorer mechanical properties than those from the non-aqueous method. This can be explained due to the removal of the sizing of the glass fiber immersed in water (the aqueous method). Analysis through SEM micrographs of the "dry" glass fiber and of the glass fiber after its contact with the distilled water (Figure 8) confirmed the removal of the sizing, which is in agreement with the literature ${ }^{6}$.

\section{Conclusions}

The composites containing only sisal fibers absorbed around 15 times more water than those containing only glass fibers. The

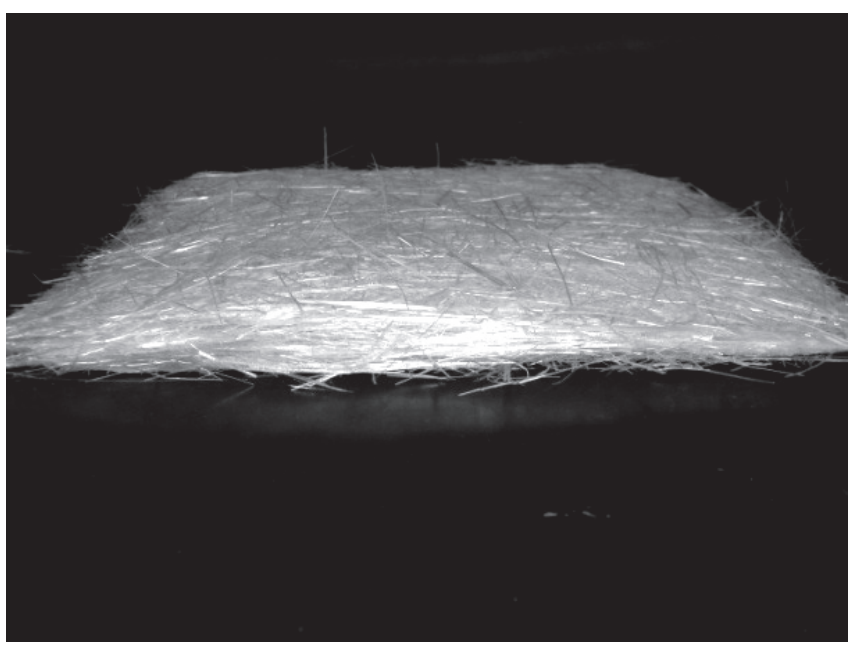

(b)

(a)

Figure 5. Hybrid mat (50\% glass fiber / 50\% sisal fiber) manufactured with the aqueous method: (a) superior view and (b) side view.

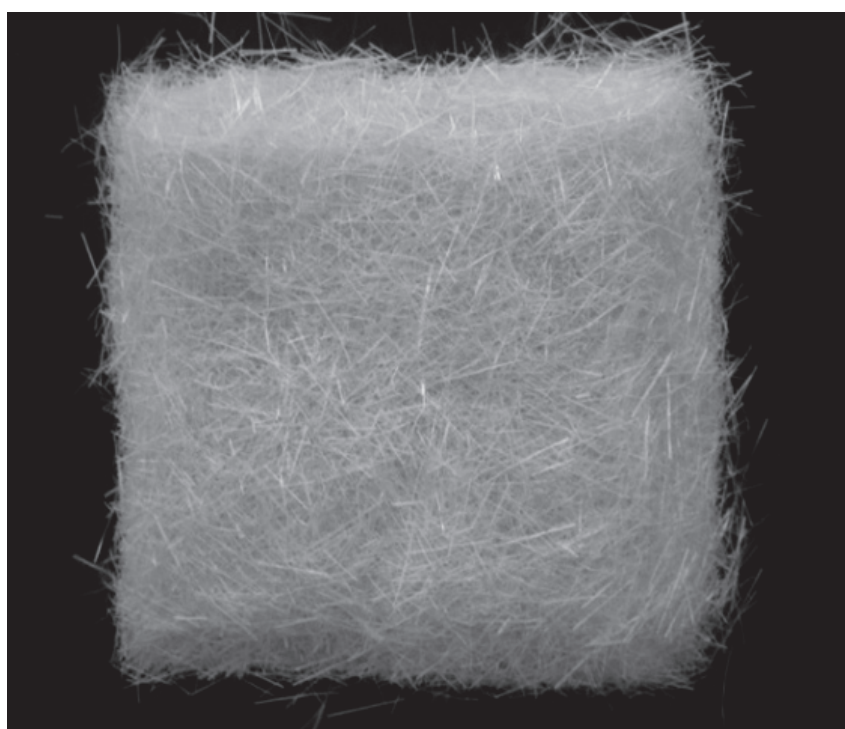

(a)

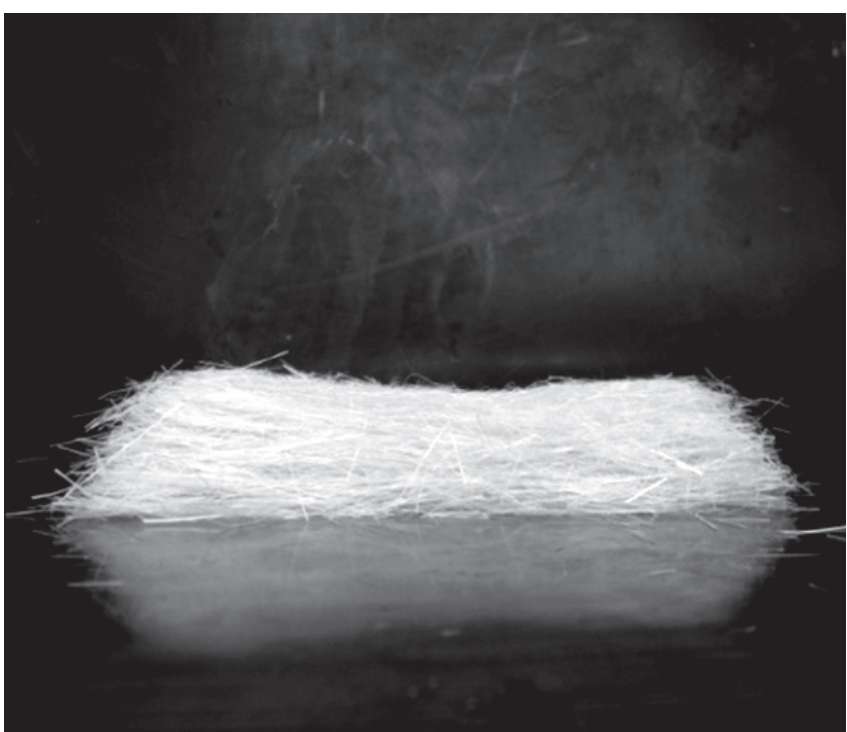

(b)

Figure 6. Hybrid mat (50\% glass fiber / 50\% sisal fiber) manufactured with the non-aqueous method: (a) superior view and (b) side view. 


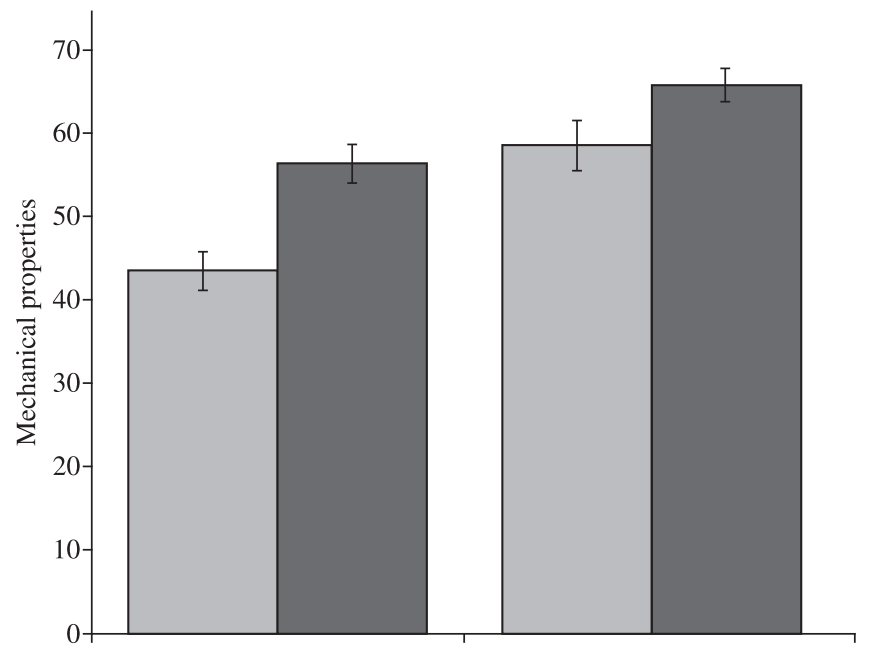

Aqueous

Fluidized

Glass fiber content (50\% vol.)

Tensile sterngth (MPa)

Impact strength $\left(\mathrm{kJ} . \mathrm{m}^{-2}\right)$

Figure 7. Tensile Strength and impact strength of the composites in relation to the manufacturing method of the hybrid mat (50\% glass fiber / $50 \%$ sisal fiber).

increase in glass fiber content yields an increase in tensile strength. The impact results showed that an increase in glass fiber content generates an increase in impact strength. The mats manufactured with the fluidized bed method showed less agglomeration of fibers, promoting resin flow within the mat. The composites obtained with mats produced with the aqueous method showed poorer mechanical properties than those from the non-aqueous method.

\section{Acknowledgements}

The authors thank the support of the following institutions: UCS, UFRGS and CAPES.

\section{References}

1. El-Tayeb NSM. A study on the potential of sugarcane fibers/polyester composite for tribological applications. Wear. 2008; 265(1-2):223-235.

2. Idicula M, Boudenne A, Umadevi L, Ibos L, Candau Y and Thomas S. Thermophysical properties of natural fibre reinforced polyester composites. Composites Science and Technology. 2006; 66(15):2719.

3. Joshi SV, Drzal LT, Mohanty AK and Arora S. Are natural fiber composites environmentally superior to glass fiber reinforced composites? Composites Part A: Applied science and manufacturing. 2004; 35(3):371.

4. Ahmed KS, Vijayarangan S and Naidu ACB. Elastic properties, notched strength and fracture criterion in untreated woven jute-glass fabric reinforced polyester hybrid composites. Materials \& Design. 2007; 28(8):2287.

5. D'Almeida JRM and Monteiro SN. Compósitos reforçados por fibras naturais: oportunidades e desafios. In: Anais do 58 Congresso Anual da Associação Brasileira de Metalurgia e Materiais; 2003; São Paulo: ABM; 2003. p. 1725-1734.

6. Mallarino S, Chailan JF and Vernet JL. Glass fibre sizing effect on dynamic mechanical properties of cyanate ester composites I. Single frequency investigations. European Polymer Journal. 2005; 41(8):1804.

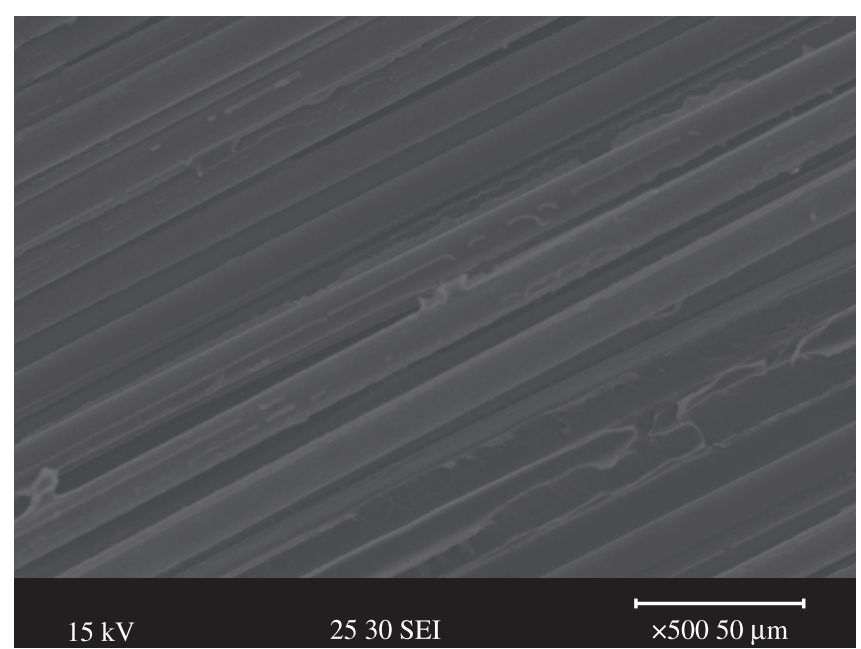

(a)

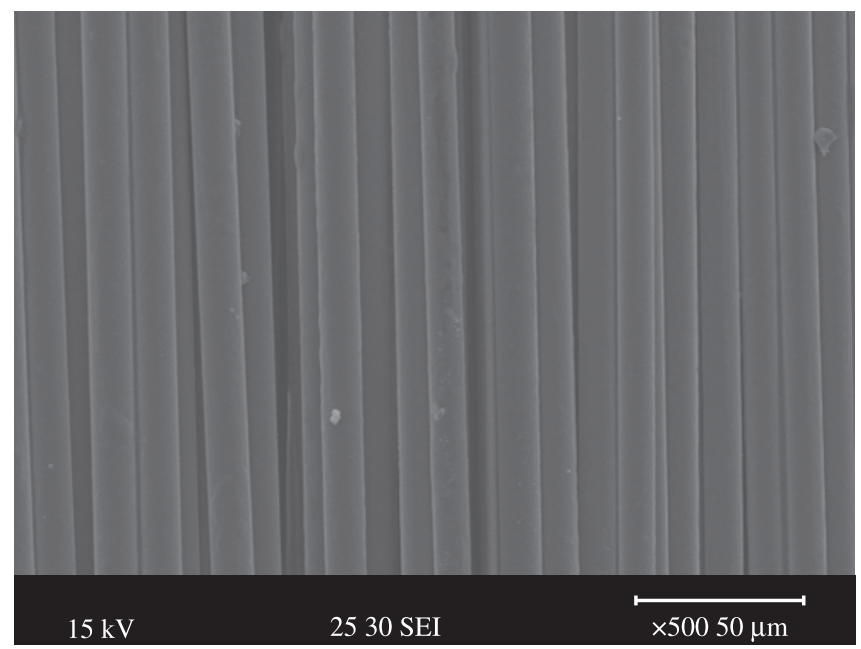

(b)

Figure 8. SEM micrographs of glass fibers (a) dry and (b) after washing in distilled water.

7. Frazer WA, Ancker FH, Dibenedetto AT and Elbirli B. Evaluation of surface treatments for fibers in composite materials. Polymer Composites; 1983; 4(4):238.

8. American Society for Testing and Materials - ASTM. Norma ASTM D570. Standard test method for water absorption of plastics. Philadelphia: ASTM; 1998.

9. American Society for Testing and Materials - ASTM. Norma ASTM D792. Standard test methods for density and specific gravity (relative density) of plastics by displacement. Philadelphia: ASTM; 1998.

10. American Society for Testing and Materials - ASTM. Norma ASTM D3039. Standard test method for tensile properties of polymer matrix composite materials. Philadelphia: ASTM; 2003.

11. American Society for Testing and Materials - ASTM. Norma ASTM D256. Standard test methods for determining the izod pendulum impact resistance of plastics. Philadelphia: ASTM; 2004.

12. Wambua P, Ivens $J$ and Verpoest I. Natural fibres: can they replace glass in fibre reinforced plastics? Composites Science and Technology. 2003; 63(9):1259.

13. Dhakal HN, Zhang ZY, Richardson MOW and Errajhi OAZ. The low velocity impact response of non-woven hemp fibre reinforced unsaturated polyester composites. Composites Structures. 2007; 81(4):559. 